\title{
Gonadotrophin secretion and pituitary responsiveness to LHRH in castrated and intact male rabbits exposed to different photoperiods
}

\author{
I. L. Boyd \\ Institute of Terrestrial Ecology, Monks Wood Experimental Station, Abbots Ripton, Huntingdon, \\ Cambs PE17 2LS, U.K.
}

\begin{abstract}
Summary. Adult male wild rabbits were exposed to at least 16 weeks of $16 \mathrm{~L}: 8 \mathrm{D}$ before experiments began. Plasma LH and FSH concentrations increased significantly $(P<0.001)$ when rabbits were castrated in $16 \mathrm{~L}: 8 \mathrm{D}$ but declined when rabbits were transferred to $8 \mathrm{~L}: 16 \mathrm{D}$. Concentrations had returned to normal for castrated rabbits in $16 \mathrm{~L}: 8 \mathrm{D}$ by 74 days after the start of the $8 \mathrm{~L}: 16 \mathrm{D}$ treatment. Treatment of intact male rabbits with an injection of LHRH before and after transfer to short daylengths caused a transient increase in plasma $\mathrm{LH}$ which lasted $50-80 \mathrm{~min}$ and this produced a concomitant rise in plasma testosterone. The daylength change had no effect on this response even though testicular size declined after the transfer to short daylengths. Rabbits moulted in response to exposure to $8 \mathrm{~L}: 16 \mathrm{D}$. This suggests that hypothalamic activity responds to photoperiod and that changes in pituitary responsiveness to LHRH and steroid negative feedback are unimportant.
\end{abstract}

\section{Introduction}

Rabbits (Oryctolagus cuniculus) in the wild have an annual cycle of reproduction which is shown in males by significant seasonal changes in testicular size (Andersson et al., 1979; Boyd, 1985). As for many other mammals (Sadleir, 1969; Lincoln \& Short, 1980) this cycle is affected by seasonal changes in daylength (Boyd, 1985, 1986a). It has long been established for mammals that daylength is transduced to an endocrine signal via the pineal gland (Reiter, 1980) but it is still unclear exactly how the link between the pineal and the hypothalamo-hypophysial axis operates to stimulate or inhibit breeding. Some studies have suggested that the ultimate effect of changes in daylength is to cause changes in the sensitivity of this axis to negative feedback by gonadal steroids (Legan et al., 1977; Lincoln, 1977; Goodman \& Karsch, 1981). However, other studies have produced good evidence for gonadotrophin secretion being more directly controlled by photoperiod (Turek et al., 1975; Pelletier \& Ortavant, 1975; Ellis \& Turek, 1980; Simpson et al., 1982; Lincoln, 1984).

If negative feedback relies entirely on gonadal steroid hormones, then gonadectomy should release this inhibition on gonadotrophin release. Plasma concentrations of gonadotrophins should then increase and, if changing sensitivity to gonadal steroids is important in causing seasonal gonadal regression, then plasma gonadotrophin values would be expected to remain elevated even when animals are exposed to the short daylengths that would normally induce gonadal regression. Alternatively, a decline in plasma gonadotrophin concentrations after gonadectomy and then transfer to an inhibitory daylength would suggest that sensitivity to steroid negative feedback is less important than regulation of gonadotrophin release by other more direct mechanisms. Measuring the responsiveness of the anterior pituitary to luteinizing hormone-releasing hormone (LHRH) (Carlson \& Perrin, 1979) will show whether changes in pituitary physiology are involved in this process. The present study investigates these hypotheses in wild-caught rabbits. 


\section{Materials and Methods}

Study animals. Adult male wild rabbits were captured on farmland in Cambridgeshire, U.K., during October and November. Adults were distinguished from juveniles by the presence of descended testes and the degree of ossification of the proximal apophysis of the tibia (Thompson \& Worden, 1956). Rabbits were caged individually in lightproof rooms where daylight was simulated with cold fluorescent lamps under the control of electrical time switches. Food, which was a standard diet of rabbit pellets, and water were freely available to each rabbit throughout the study. Temperature was not closely controlled but varied within the same limits for all rabbits. Rabbits were exposed to 16-20 weeks of $16 \mathrm{~h}$ light:8 $\mathrm{h}$ darkness (16L:8D) before experiments began.

Experiment 1. Twelve rabbits were assigned to 3 groups at random after the pretreatment period in long daylengths. Group 1 ( 4 rabbits) was maintained in 16L:8D throughout the experiment ( 88 days). Groups 2 and 3 (4 rabbits each) were anaesthetized with an injection (i.m.) of $0.4 \mathrm{ml}$ Hypnorm, containing fentanyl $(0.20 \mathrm{mg} / \mathrm{ml})$ and fluanisone $(10 \mathrm{mg} / \mathrm{ml})$ (Janssen Pharmaceutical Ltd., Grove, Oxford OXI2 0DQ, U.K.), and castrated on Day 1. Group 2 was kept in 16L:8D for the remainder of the experiment while Group 3 was kept in 16L:8D for a further 13 days and then transferred to $8 \mathrm{~L}: 16 \mathrm{D}$ for the remainder of the experiment. Blood samples $(1-2 \mathrm{ml})$ were obtained from the ear vein at intervals throughout the experiment, the frequency of sampling being determined by expected rates of change in plasma hormones. Each rabbit was given an injection (i.m.) of 0.15 ml Hypnorm 5-10 min before sampling to encourage blood flow to the ears and to induce mild anaesthesia. All rabbits weighed between 1400 and $1600 \mathrm{~g}$. Blood samples were centrifuged and the plasma stored at $-20^{\circ} \mathrm{C}$.

Experiment 2. Eleven rabbits were allocated at random to 2 groups after the pretreatment in long daylengths. Group 4 ( 3 rabbits) was maintained in 16L:8D throughout the experiment ( 23 weeks). Group 5 ( 8 rabbits) was transferred to short daylengths during Week 3. During Weeks 2, 6 and 12 all rabbits were treated (i.v.) with a single injection of $1 \mu \mathrm{g}$ synthetic LHRH (acetate salt dissolved in autoclaved saline) (Sigma Chemical Company Ltd, Poole, Dorset $\mathrm{BH} 17 \mathrm{NHH}, \mathrm{U} . \mathrm{K}$.). After the injection, blood $(1 \mathrm{ml})$ was sampled from an ear vein at 10 -min intervals for $90 \mathrm{~min}$. Rabbits were kept lightly anaesthetized throughout this procedure as described for Exp. 1. Blood samples were centrifuged and stored at $-20^{\circ} \mathrm{C}$.

The testicular size of all rabbits was measured at weekly intervals. Testes were manipulated into the scrotum and the total length of the testis, including the head and tail segments of the epididymis, was measured to the nearest $0.1 \mathrm{~mm}$. The maximum testicular width was also measured to the same accuracy and the presence or absence of moult was recorded.

Radioimmunoassays. Plasma LH, FSH and testosterone radioimmunoassays were carried out as described by Boyd (1986a). Samples from Exp. 1 were assayed for LH and FSH while those for the LHRH treatments in Exp. 2 were analysed for LH and testosterone. Both LH and FSH were measured in single assays which had sensitivities of 0.2 and $0.4 \mathrm{ng} / \mathrm{ml}$ plasma respectively and intra-assay coefficients of variation of $8.6 \%$ and $15.7 \%$ respectively. Highly purified rabbit LH and FSH were used as standards. The testosterone assay had a sensitivity of $0.07 \pm 0.01 \mathrm{ng} / \mathrm{ml}$ plasma. The intra- and inter-assay coefficients of variation were $5 \cdot 5$ and $\mathbf{9 \cdot 4} \%$ respectively.

Statistical procedures. Estimates of testicular weight were calculated from the measurements of length and width using the formula given by Boyd (1986a). Differences between groups were evaluated with two-tailed $t$ tests. Analysis of variance by repeated measures (Sokal \& Rohlf, 1981) was used to evaluate changes in testicular size and hormone concentration with time. A probability of $<0.05$ was assumed to be significant.

\section{Results}

\section{Experiment 1}

Plasma LH and FSH concentrations of Group 1 rabbits remained low throughout the experiment (Fig. 1), in contrast with Groups 2 and 3 in which plasma FSH increased by $20-30$ times and LH by $2-4$ times after castration (Days $1-16, P<0.001$ in each case). There was no significant difference in plasma $\mathrm{LH}$ and FSH concentrations between Groups 2 and 3 before the transfer to short daylengths.

After transfer to short daylengths, plasma LH declined in Group 3 until Day 47 when it began to increase (Days 15-88, $\mathrm{F}(10,30)=2 \cdot 66, P<0.05$ ) (Fig. 1a). This increase was sustained until the end of the experiment. In contrast, plasma LH values in Group 2, which was kept in constant long daylengths throughout, showed no significant variation over the same period $(\mathrm{F}(10,30)=0 \cdot 61$, $P>0.05$ ) (Fig. 1a). On Day 47 plasma LH concentrations in Group 3 were significantly lower than in Group $2(t=3 \cdot 741$, d.f. $=6, P<0 \cdot 01)$.

Plasma FSH concentrations also declined in Group 3 after the transfer to short daylengths and 

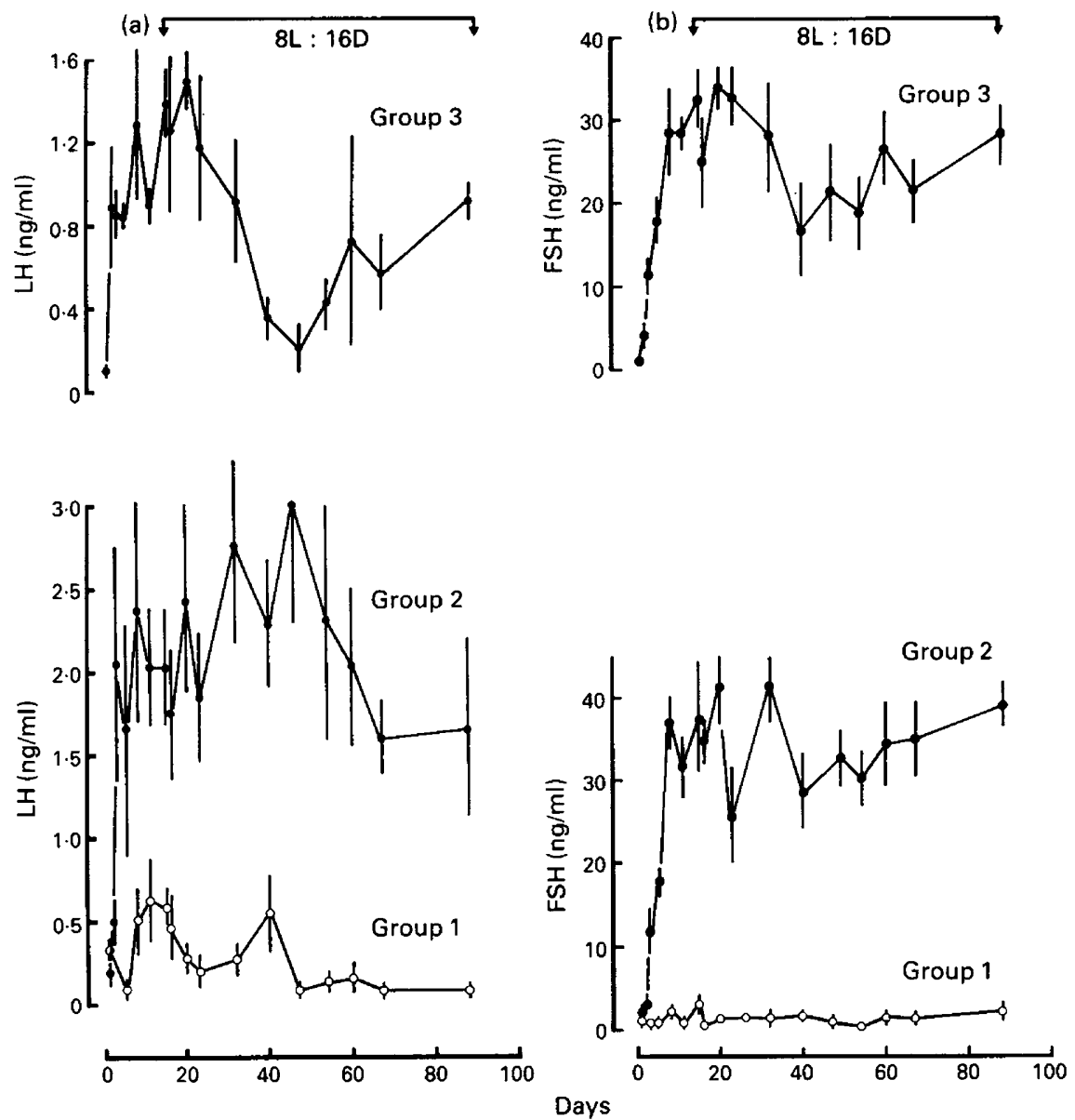

Fig. 1. Changes in the mean ( \pm s.e.m.) plasma LH (a) and FSH (b) concentrations in intact $(O$, $N=4)$ and castrated $(\Theta, N=4)$ male rabbits in $16 \mathrm{~L}: 8 \mathrm{D}$. Group 3 rabbits $(N=4)$ were transferred to $8 \mathrm{~L}: 16 \mathrm{D}$ on Day $14(\downarrow-\downarrow)$. All rabbits were pretreated with at least 16 weeks of $16 \mathrm{~L}: 8 \mathrm{D}$.

this was followed by a slow increase (Days $15-88, \mathrm{~F}(10,30)=2 \cdot 37, P<0 \cdot 05$ ) (Fig. 1b). No significant change occurred in plasma $F S H$ values in Group 2 over the same period $(F(10,30)=1 \cdot 78$, $P>0 \cdot 05$ ). However, unlike plasma LH, there were no significant differences between plasma FSH values in Groups 2 and 3 on any sampling date after Day 16.

Rabbits in Group 3 were in full moult on Day 60 while rabbits in the other two groups did not moult during the experiment.

\section{Experiment 2}

After transfer to short daylengths during Week 3, the testicular size of rabbits in Group 5 declined (Weeks $1-10, \mathrm{~F}(9,63)=29.57, P<0.001$ ) (Fig. 2). This decline was followed by moult during Weeks 8-10 and a significant testicular regrowth (Weeks $10-23, \mathrm{~F}(13,91)=3.42, P<0.01$ ) to a weight similar to that before the transfer to short daylengths. During Weeks 6-15 testicular weight in Group 5 was significantly lower than that for Group $4(P<0.05$ in each week) kept in constant long daylengths (Fig. 2). However, testicular size in Group 4 declined during the study 


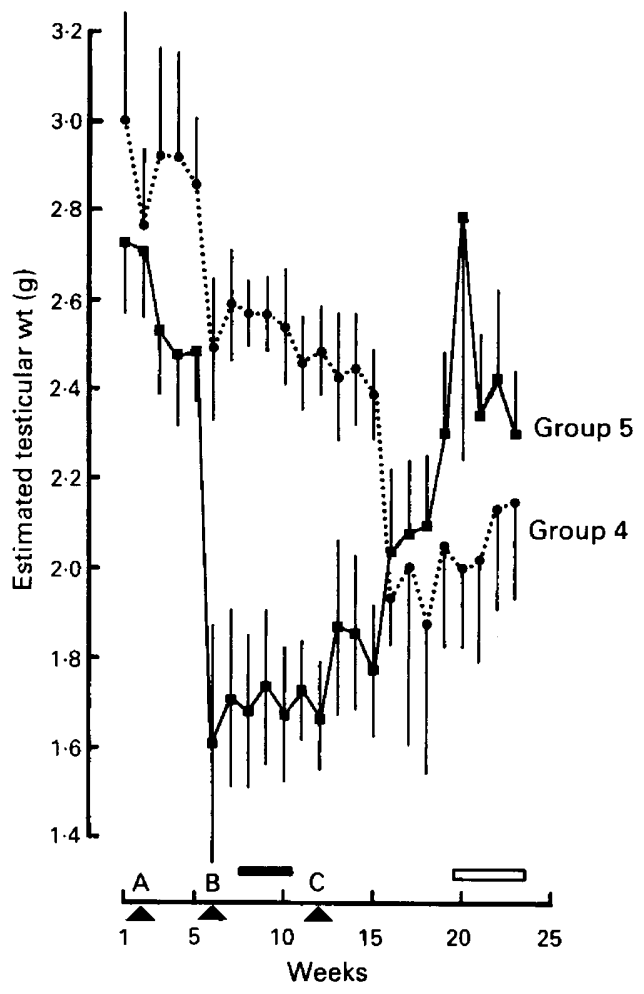

Fig. 2. Changes in the mean ( \pm s.e.m.) estimated testicular weight of rabbits transferred from 16L:8D to $8 \mathrm{~L}: 16 \mathrm{D}$ during Week $3(-\mathbf{-}-)$ and kept in $16 \mathrm{~L}: 8 \mathrm{D}$ throughout $(\cdots \cdots)$. All rabbits were pretreated with at least 16 weeks of $16 \mathrm{~L}: 8 \mathrm{D}$. The time of moult is shown by the open bar for Group 4 and by the closed bar for Group 5. The arrows on the time axis (A, B and C) show when rabbits were treated with an injection of LHRH (see text and Fig. 3).

$(\mathrm{F}(22,44)=8 \cdot 76, P<0.01)$ and this decline was particularly rapid between Weeks 14 and 15 . Rabbits in Group 4 moulted during Weeks 20-23.

The general effect of the injection of LHRH was an immediate increase in plasma LH which reached a peak 10-40 min after the injection and had returned to basal levels 50-80 min later (Fig. 3). Plasma testosterone values began to increase $10-15 \mathrm{~min}$ after the injection and this increase coincided with the $\mathrm{LH}$ peak. Plasma testosterone reached an asymptote $30-40 \mathrm{~min}$ after the injection but remained elevated for the rest of the sampling period ( $90 \mathrm{~min}$ ) (Fig. 3).

There was no significant difference between Groups 4 and 5 in their plasma LH profiles when tested at Weeks 2 and 6, but during Week 12 plasma LH concentration was significantly higher in Group 5 than in Group 4, 10 min after the injection $(t=6.69$, d.f. $=9, P<0.001)$. This was because, during Week 12, plasma LH was slower to respond to the LHRH injection in Group 4 compared with Group 5 (Fig. 3).

The profiles of plasma testosterone were not altered significantly by the stage of development of the testes (Figs $2 \& 3$ ) and did not differ between Groups 4 and 5. However, the increase in plasma testosterone during Week 12 appeared to be slower in Group 4 than Group 5.

\section{Discussion}

The reduced plasma concentrations of gonadotrophins resulting from exposure of castrated rabbits to short daylengths after a period in long daylengths coincided with testicular regression when 


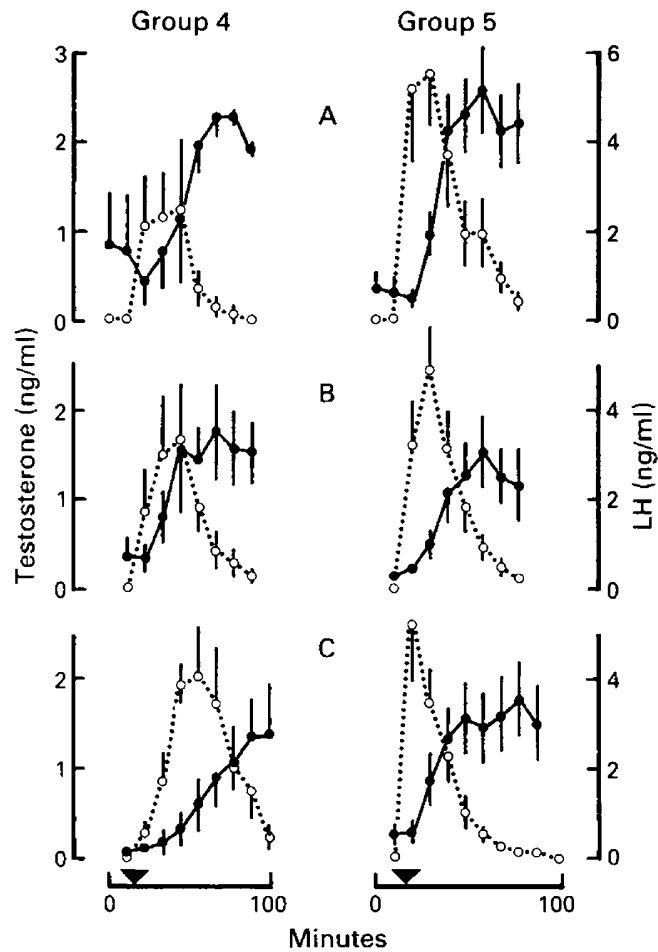

Fig. 3. Profiles of mean ( \pm s.e.m.) plasma LH $(\cdots \circ \cdots)$ and testosterone $(-0-)$ concentrations in Groups 4 and 5 after a single injection of LHRH ( $\boldsymbol{\nabla})$ at times A, B and C corresponding to those shown on the time axis of Fig. 2 (A, B and C).

intact rabbits were exposed to a similar daylength regimen (Fig. 3) (Boyd, 1985, 1986a). This agrees with observations for other seasonally breeding mammals, such as hamsters (Simpson et al., 1982; Urbanski \& Simpson, 1982, 1983; Urbanski et al., 1983), ground squirrels (Zucker \& Licht, 1983) and sheep (Pelletier \& Ortavant, 1985) in which, after gonadectomy, gonadotrophin concentrations declined during the inactive phase of the reproductive cycle. A similar response has also been found in some birds (Storey \& Nicholls, 1981; Dawson \& Goldsmith, 1984). Removal of gonadal steroids, therefore, did not nullify the response to photoperiod in rabbits and, since pituitary responsiveness to LHRH did not decline after transfer to short daylengths, daylength primarily affects a hypothalamic component of the reproductive system.

It took several weeks for plasma gonadotrophins to reach minimal values after the transfer to short daylengths, but this slow rate of change corresponds with a delay of 3-4 weeks before significant testicular regression occurs (Fig. 2). However, castration may have affected hypothalamopituitary physiology to reduce the decline in $\mathrm{LH}$ and FSH which would normally occur at this time (Urbanski \& Simpson, 1983). These results, together with those from the LHRH injections, give no indication that changing sensitivity to gonadal steroid feedback is a major factor in the seasonal regression or regrowth of the gonads in male rabbits. However, gonadotrophin secretion was not fully suppressed after transfer from long to short daylengths and so it is still possible that some dependence on steroid negative feedback exists (Turek \& Ellis, 1981).

The testes of wild rabbits can still produce testosterone in response to stimulation by $\mathrm{LH}$, even when in the regressed state (Exp. 2). Boyd (1985) showed that rabbits in the laboratory with regressed testes had reduced spermatogenesis, indicating that the response of the reproductive system of male rabbits to seasonal changes in daylength may be manifest more as increased and 
decreased fertility rather than an event which is switched on or off as in the starling (Dawson \& Goldsmith, 1984).

Boyd (1986a) found low plasma LH and testosterone concentrations in anaesthetized intact male rabbits throughout periods of rapid gonadal development and regression. The same opioid anaesthetic was used in this study. Opioids are known to reduce pulsatile LH secretion in Soay rams through their effect on LHRH release (Ebling \& Lincoln, 1985). Consequently, the release of LH may have been affected by the anaesthetic although, in this study, plasma LH and FSH concentrations still increased after castration. This suggests that gonadal steroids may have a role in sensitizing rabbits to the effects of opioids.

Exposure of rabbits to short daylengths after at least 16 weeks in long daylengths can induce testicular regression (Boyd, 1985, 1986a). However, prolonged exposure to long daylengths also caused testicular regression (Fig. 2) which agrees with the hypothesis that long daylengths are responsible for the development of a process of inhibition of reproductive activity which eventually leads to regression of the gonads (Robinson \& Follett, 1982; Boyd, 1986b).

I thank Mr D. G. Myhill for assistance and Dr A. F. Parlow for supplying the LH and FSH antisera and standards.

\section{References}

Andersson, M., Dahlback, M. \& Meurling, P. (1979) Biology of the wild rabbit, Oryctolagus cuniculus, in southern Sweden. I. Breeding season. Swedish Wildl. Res. 11, 103-127.

Boyd, I.L. (1985) Effect of photoperiod and melatonin on testis development and regression in wild European rabbits (Oryctolagus cuniculus). Biol. Reprod. 33, 21-29.

Boyd, I.L. (1986a) Photoperiodic regulation of seasonal testicular regression in the wild European rabbit (Oryctolagus cuniculus). J. Reprod. Fert. 77, 463-470.

Boyd, I.L. (1986b) Effect of daylength on the breeding season in male rabbits. Mam. Rev. 16, 125-130.

Carlson, J.C. \& Perrin, D.G. (1979) The effect of LH-RH administration on $\mathrm{LH}$ release in the female rabbit. $J$. Reprod. Fert. 56, 175-180.

Dawson, A. \& Goldsmith, A.R. (1984) Effects of gonadectomy on seasonal changes in plasma $\mathrm{LH}$ and prolactin concentrations in male and female starlings (Sturnus vulgaris). J. Endocr. 100, 213-218.

Ebling, F.J.P. \& Lincoln, G.A. (1985) Endogenous opioids and the control of seasonal LH secretion in Soay rams. J. Endocr. 107, 341-353.

Ellis, G.B. \& Turek, F.W. (1980) Photoperiodic regulation of serum luteinizing hormone and follicle stimulating hormone in castrated and castratedadrenalectomized male hamsters. Endocrinology 106, 1338-1344.

Goodman, R.L. \& Karsch, F.J. (1981) A critique of the evidence on the importance of steroid feedback to seasonal changes in gonadotrophin secretion. $J$. Reprod. Fert., Suppl. 30, 1-13.

Legan, S.J., Karsch, F.J. \& Foster, D.L. (1977) The endocrine control of seasonal reproductive function in the ewe: a marked change in response to the negative feedback action of estradiol on luteinising hormone secretion. Endocrinology 101, 818-824.
Lincoln, G.A. (1977) Changes in pituitary responsiveness to luteinising hormone releasing hormone in rams exposed to artificial photoperiods. J. Endocr. 73, 519-527.

Lincoln, G.A. (1984) Central effects of photoperiod on reproduction in the ram revealed by the use of a testosterone clamp. J. Endocr. 103, 233-241.

Lincoln, G.A. \& Short, R.V. (1980) Seasonal breeding: Nature's contraceptive. Recent Prog. Horm. Res. 36, $1-52$.

Pelletier, J. \& Ortavant, R. (1975) Photoperiodic control of $\mathrm{LH}$ release in the ram. I. Influence of increasing and decreasing light photoperiods. Acta endocr., Copenh. 78, 435-441.

Reiter, R.J. (1980) The pineal and its hormones in the control of reproduction in mammals. Endocr. Rev. 1, 109- \3!.

Robinson, J.E. \& Follett, B.K. (1982) Photoperiodism in Japanese quail: termination of seasonal breeding by photorefractoriness. Proc. R. Soc. Lond. B 215, 95-116.

Sadlier, R.M.F.S. (1969) The Ecology of Reproduction in Wild and Domestic Mammals. Methuen, London.

Simpson, S.M., Follett, B.K. \& Ellis, D.H. (1982) Modulation by photoperiod of gonadotrophin secretion in intact and castrated Djungarian hamsters. J. Reprod. Fert. 66, 243-250.

Sokal, R.R. \& Rohlf, F.J. (1981) Biometry. Freeman and Company, San Francisco.

Storey, C.R. \& Nicholls, T.J. (1981). The effect of testosterone upon a photoperiodically induced gonadal cycle of gonadotrophin secretion in castrated canaries, Serinus canarius. Gen. comp. Endocr. 43, 527-531.

Thompson, H.V. \& Worden, A.N. (1956) The Rabbit. Collins, London.

Turek, F.W. \& Ellis, G.B. (1981) Steroid dependent and 
steroid independent aspects of the photoperiodic control of seasonal reproductive cycles in male hamsters. In Biological Clocks in Seasonal Reproductive Cycles, pp. 251-260. Eds B. K. Follett \& D. E. Follett. Wright, Bristol.

Turek, F.W., Elliott, J.A., Alvis, J.D. \& Menaker, M. (1975) The interaction of castration and photoperiod in the regulation of hypophyseal and serum gonadotropin levels in male golden hamsters. Endocrinology 96, $854-860$.

Urbanski, H.F. \& Simpson, S.M. (1982) Photoperiodic suppression of gonadotrophin secretion in castrated male hamsters. J. Reprod. Fert. 66, 299-303.

Urbanski, H.F. \& Simpson, S.M. (1983) Effects of shortterm treatment with testosterone on the secretion of FSH and LH in castrated golden hamsters exposed to short days. J. Reprod. Fert. 69, 489-496.
Urbanski, H.F., Simpson, S.M., Ellis, D.H. \& Follett, B.K. (1983) Secretion of follicle-stimulating hormone and luteinizing hormone in castrated golden hamsters during exposure to various photoperiods and to natural daylengths. $J$. Endocr. 99, 379-386.

Zucker, I. \& Licht, P. (1983) Circannual and seasonal variation in plasma luteinizing hormone levels of ovariectomized ground squirrels (Spermophilus lateralis). Biol. Reprod. 28, 178-185.

Received 14 August 1986 